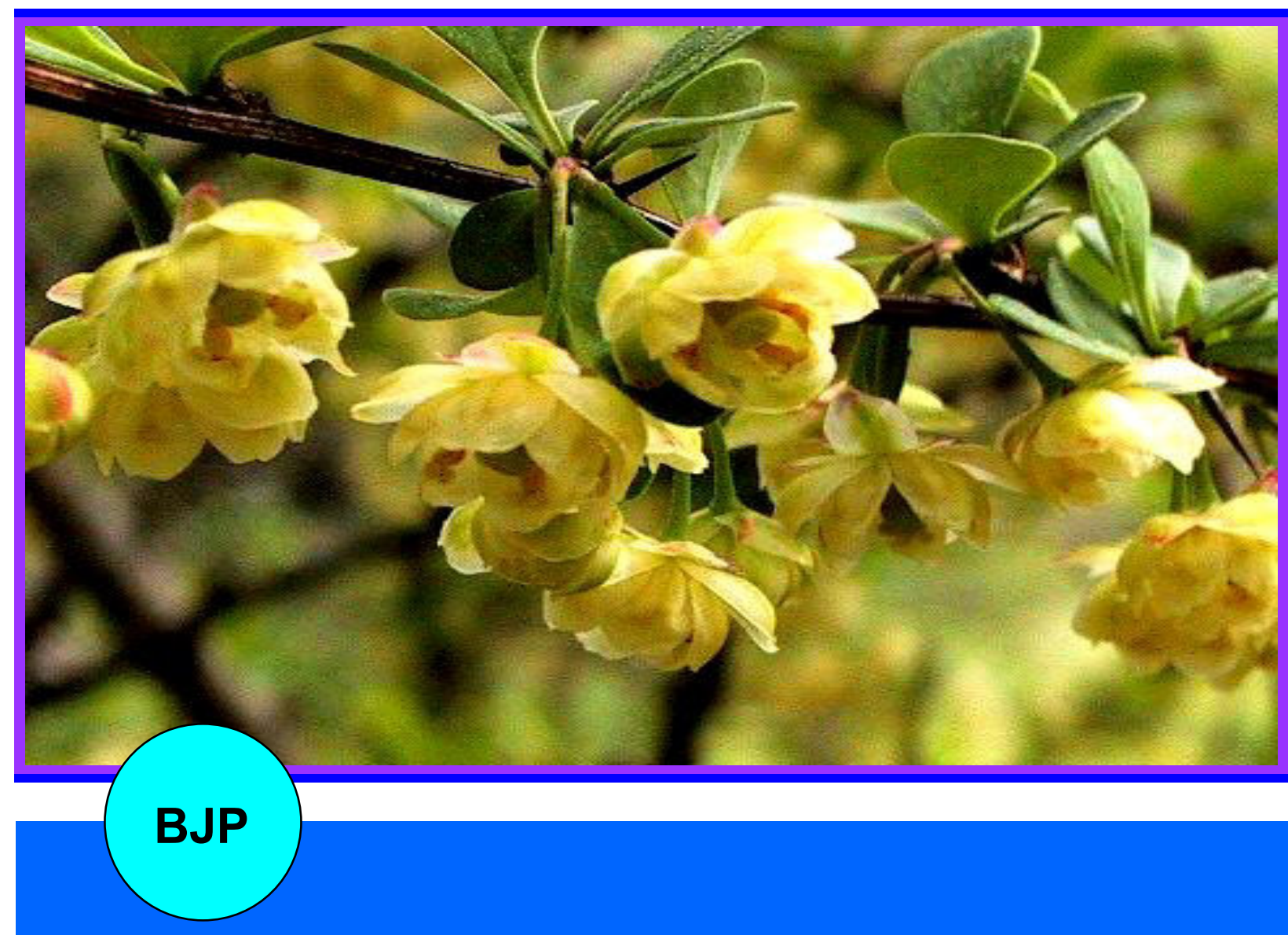

Bangladesh Journal of Pharmacology

Research Article

Evaluation of anticoagulant and thrombolytic activity of Berberis orthobotrys in animal model 


\title{
Evaluation of anticoagulant and thrombolytic activity of Berberis orthobotrys in animal model
}

\author{
Alamgeer ${ }^{1}$, Mahpara Tarar', Umme Habiba Hasan' ${ }^{1}$ and Muhammad Saleem² \\ ${ }^{1}$ Laboratory of Cardiovascular Research and Integrative Pharmacology, College of Pharmacy University of \\ Sargodha, Sargodha, Pakistan; ${ }^{2}$ University College of Pharmacy, University of Punjab, Punjab, Pakistan.
}

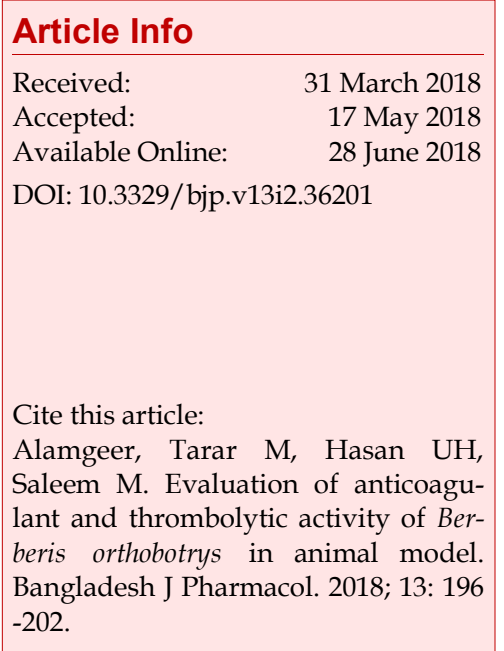

\begin{abstract}
Fundamental to this research was the evaluation of anticoagulant and thrombolytic potential of Berberis orthobotrys using clotting time, prothrombin time and activated partial thromboplastin time performed at $2.5,5,10 \%$ concentration. Aqueous-methanol extract significantly $(p<0.05)$ increased the coagulation parameters both in human blood as well as in rabbit blood and exhibited the more salient effect on prolongation of these coagulation parameters at $10 \%$ concentration. Aqueous methanol extract $(25,50$ and $100 \mathrm{mg} / \mathrm{kg}$ ) produced the preferential increase in bleeding time and clotting time nevertheless the effect was more perceptible after $90 \mathrm{~min}$ at $100 \mathrm{mg} / \mathrm{kg}$. Moreover, the crude extract presented a substantial increase in coagulation parameters after 7 days of administration in rabbits with more pronounced effects at the highest dose. HPLC profile of aqueous methanol extract revealed the presence of quercetin, p-coumaric acid, gallic acid, vanillic acid, 4-hydroxy-3-methoxy benzoic acid. Thus, the present study provides the pharmacological basis for its medical use in cardiovascular and other thrombotic disorders.
\end{abstract}

\section{Introduction}

Blood coagulation is a defense mechanism to maintain the veracity of closed, high-pressure mammalian circulatory system after blood vessel injury. Blood coagulation abnormalities result in thrombosis, atherosclerosis and inflammation by the activation of enzymes in coagulation cascade and platelets (Gou et al., 2003). The stages of coagulation, therefore, include vessel constriction, platelet plug formation, coagulation as well as fibrin generation and healing and repair (Anderson and Spencer, 2003). However, three principal factors for thrombus formation are so-called Virchow's triad i.e., endothelial injury, blood flow stasis or turbulence and hyper-coagulability of blood (Adiba et al., 2013).

In the developed countries, thromboembolic disorders such as pulmonary emboli, deep vein thrombosis, strokes and heart attacks are the main causes of morbidity and mortality (Dickneite et al., 1995). The use of anti- coagulant (heparin, warfarin) is linked to many limitations and adverse effects. The most incurable complication associated with this therapy is bleeding. Other adverse effects also limit the use of anticoagulants like, heparin-induced thrombocytopenia, drug-drug interactions, erratic dose-response relationship, and forceful monitoring need and in some cases reocclusion may occur. Conventional medicine has been defined as knowledge of collection, skills and practices which are based on the theories and views of different cultures that help in health maintenance as well as in prevention, diagnosis, improvement or treatment of physical and mental illness (Mahmood et al., 2011). Herbal medicine has been frequently used for historical, cultural and biological reasons due to their easy, continued availability (Bhattarai, 1989), better compatibility and also because of less testing time, higher safety, improved efficacy, compliance, least adverse effects and cost-effectiveness (Khanna et al., 1986). 
As the medicinal plants like Berberis calliobotrys (Alamgeer et al., 2016), Careya arborea, Melastoma malabathricum, Eichhornia crassipe, Jatropha curcas and Mentha longifolia (Alamgeer et al., 2018), Porana volubilis etc are the pool of many cheap and safe therapeutic agents (Jain et al., 2014). A traditional medicinal plant namely, Berberis orthobotrys Bien ex Aitch was selected for the current research work and an attempt made for the confirmation of possible antithrombotic effects of the selected plant so that it could be helpful in the therapy of thrombotic disorders (Khan and Khatoon, 2007).

\section{Materials and Methods}

\section{Chemicals and reagents used in the present research}

Trisodium citrate, heparin (Leo Pharmaceuticals, Denmark), methanol (Merck, Germany), prothrombin reagent, activated partial thromboplastin reagent (Mac and Rains Pharmaceuticals, Pakistan) were purchased from the relevant companies.

\section{Experimental animals}

Healthy adult rabbits of either sex, weighing from 1.0$1.5 \mathrm{~kg}$ of 10-12 months were used. Rabbits were kept in a fine lighted air-conditioned room $\left(26 \pm 1^{\circ} \mathrm{C}\right)$ under standard environmental conditions (12 hours light-dark cycles). They were fed on standard green leafy, seasonal vegetables, green leaves of alfalfa and water ad libitum. In vitro studies were also performed on the blood samples obtained from the healthy human.

\section{Collection and authentication of medicinal plant}

B. orthobotrys roots were collected from the District Gilgit, Pakistan during the month of June 2014 and was identified and authenticated by Dr. Shair Wali, Department of Botany, Karakurum International Univer-sity, Gilgit, Baltistan, Pakistan. A voucher (No. BO-15-12) has been deposited in the herbarium, Faculty of Pharmacy, University of Sargodha for future reference.

\section{Preparation of aqueous methanolic extract}

By using cold maceration process, the aqueous methanolic (70:30) extract of B. orthobotrys was prepared. The grounded plant material $(2 \mathrm{~kg})$ was soaked in $5 \mathrm{~L}$ of water-methanol mixture (70:30) for 72 hours at room temperature. The whole material was filtered after three days of intermittent shaking and the filtrate evaporated under reduced pressure using rotary evaporator. The crude extract was then air-dried to obtain a solid mass with a yield of 19\% (Alamgeer et al., 2013).

\section{In vitro experiments}

\section{Effect on clotting time}

The ability of B. orthobotrys to inhibit the in vitro coagulation of blood collected either from human volunteer or rabbit was quantitatively assayed by following the procedure adopted by Koffuor and Amoateng (2011).

Aqueous methanolic extract solution of 2.5, 5 and 10\% concentrations prepared. 20 sterilized test tubes were labeled and in respective labeled test tubes, $0.2 \mathrm{~mL}$ of each extract solution was taken except first five test tubes which were used as the control for each blood sample.

One milliliter of whole blood drawn either from the healthy volunteer $(n=5)$ or rabbit $(n=5)$ was added to the test tubes and placed in a water bath at $37^{\circ} \mathrm{C}$. The time taken for the blood samples to clot was recorded with the help of stop watch (Alamgeer et al., 2016).

\section{Effect on prothrombin time and activated partial thromboplastin time}

Five labeled centrifuge tubes were taken and trisodium citrate was added. Three milliliters of blood sample was taken either from the human volunteer $(n=5)$ or rabbit $(n=5)$ and added to the centrifuge tube followed by centrifugation at 3,000 rpm for $5 \mathrm{~min}$. With the help of micropipettes, plasma was separated and saved in Eppendorf tubes. The $250 \mu \mathrm{L}$ of plant extract of varying concentrations (crude extract 2.5, 5 and 10\%) and $250 \mu \mathrm{L}$ of platelet poor plasma was mixed in an eppendorf tube and samples were incubated at $37^{\circ} \mathrm{C}$ for $5 \mathrm{~min} .100 \mu \mathrm{L}$ of test plasma and $200 \mu \mathrm{L}$ of reagent was added and clotting time was measured as prothrombin time (Alamgeer et al., 2016; Jagtap et al., 2012; Klafke et al., 2012).

For the assessment of activated partial thromboplastin time, $100 \mu \mathrm{L}$ of reagent was added to the $100 \mu \mathrm{L}$ of test plasma (platelet poor plasma + extract). The resultant mixture was heated in incubator at $37^{\circ} \mathrm{C}$ for $1 \mathrm{~min}$ after which $100 \mu \mathrm{L} \mathrm{CaCl}_{2}(25 \mathrm{mmol})$ was added and incubated for $15 \mathrm{sec}$ and clotting time was recorded as activated partial thromboplastin time (Alamgeer et al., 2016; Klafke et al., 2012).

\section{In vitro thrombolytic activity}

Solutions of different concentrations of aqueous methanolic extract $(25,50$ and $100 \mathrm{mg} / \mathrm{mL})$ were prepared. From the healthy volunteer and rabbit, venous blood was drawn. The sterile eppendorff tubes were taken and weighed them. Blood was distributed $(0.5 \mathrm{~mL} /$ tube) to each previously weighed sterile eppendorf tubes and incubated at $37^{\circ} \mathrm{C}$ for $45 \mathrm{~min}$ to form the clot. Serum was totally removed after clot formation without disturbing the clot and each tube having clot was again weighed to find out the clot weight. In each eppendorf tube containing pre-weighed clot, a volume of $100 \mu \mathrm{L}$ of test solution was added. $100 \mu \mathrm{L}$ of distilled water was separately added to the control tube numbered as a negative control. All the tubes were then incubated at $37^{\circ} \mathrm{C}$ for $90 \mathrm{~min}$ and observed for clot lysis. Fluid released was removed after incubation and tubes were again weighed to observe the difference in weight after 
clot disruption. Difference obtained in weight taken before and after clot lysis was expressed as percentage of clot lysis (Prasad et al., 2006).

\%Lysis $=$ Weight of released clot/Weight of clot X 100

Where, weight of released clot $=$ Weight of clot before lysis Weight of clot after lysis

\section{In vivo experiments}

\section{Effect on bleeding time and clotting time after single} dose administration

In vivo anticoagulant activity of $B$. orthobotrys was measured at different doses as described by Elg et al. (2001). Rabbits were divided into three groups of 5 rabbit each. Group I, II and III received aqueousmethanolic extract (25, 50 and $100 \mathrm{mg} / \mathrm{kg}$ correspondingly. At 0, 30, 60 and $90 \mathrm{~min}$, the bleeding time was recorded after administration of dose by pricking the small marginal ear vein. After every $5 \mathrm{sec}$, the pierced vein was gently blotted with the filter paper untill the cessation of bleeding.

Meanwhile, capillary tube was placed horizontally on the bleeding vein to collect the blood in it. After every $30 \mathrm{sec}$, the tube was broken until the thread of clotted blood was appeared and clotting time was recorded (Alamgeer et al., 2016).

\section{Effect on coagulation parameters after 7 days of treat- ment}

By the administration of aqueous-methanolic extract, anticoagulant prospective of the plant was explored for seven days treatment. Rabbits were divided into 4 groups of 5 rabbits each. Group I served as control. All other groups were treated orally with aqueous methanol extract $(25,50$ and $100 \mathrm{mg} / \mathrm{kg})$. Animals were kept under observation and their laboratory changes were examined on day 7 of the study. From each animal of all groups, whole blood samples were collected in capillary tubes after vein puncture and clotting time was determined by the method of the capillary tube according to the method of Elg et al. (2001) and was followed for recording the bleeding time. From each animal of all groups, about $3 \mathrm{~mL}$ of whole blood samples were collected in dry clean tubes containing trisodium citrate and was subjected to centrifugation to separate plasma which was used for measuring the prothrombin time and activated partial thromboplastin time by consuming standard reagents.

\section{Phytochemical investigation of B. orthobotrys crude extract using HPLC technique}

The sample was prepared by adopting the method of Tokusoglu et al. (2003) with slight modifications. The sample preparation was attained by mixing $50 \mathrm{mg}$ of crude aqueous methanolic extract with $16 \mathrm{~mL}$ of distilled water and $24 \mathrm{~mL}$ of methanol. Thereafter, 10 $\mathrm{mL}$ of $6 \mathrm{M} \mathrm{HCl}$ was added. The mixture was kept for 2 hours at $95^{\circ} \mathrm{C}$ in an oven to get aglycons of flavonol glycosides and then filtered via microfilter prior to injecting in HPLC. An HPLC analysis was performed using HPLC model LC-10A (Shimadzu, Japan), fitted with SCL-10A system control unit, rheodyne injector, two LC-10 AT pumps, CTO-10A column oven, SPD$10 \mathrm{~A}$ UV-Visible detector and data acquisition class LC10 software. A filtered sample $(20 \mu \mathrm{L})$ was injected into an analytical Shim-Pack CLC-ODS reverse phase (C-18) column $(25 \mathrm{~cm} \times 4.6 \mathrm{~mm} ; 5 \mu \mathrm{m}$ particle size $)$. Two solvent systems A $\left(\mathrm{H}_{2} \mathrm{O}\right.$ : Acetic acid- 94:6, $\left.\mathrm{pH}=2.27\right)$ and B (100\%acetonoitrile) were used. Graded elution of mobile phase was used to perform chromatographic separation (a mixture of solvent A and B (50:50 v/v), which was filtered using $0.5 \mu \mathrm{m}$ membrane under vacuum before use) at a flow rate of $1 \mathrm{~mL}$ per min at $30^{\circ}$ C. Detection was performed at a wavelength of $280 \mathrm{~nm}$.

\section{Statistical analysis}

The results were expressed as means \pm standard error of the mean (SEM). One-way ANOVA with posttest Dunnet's t-test was applied. In addition to this, Twoway ANOVA followed by Bonferrani test was also used for the analysis of results. The data with a confidence level of $95 \% \quad(p<0.05)$ was considered as statistically significant.

\section{Results}

Effect of B. orthobotrys on in vitro clotting time, prothrombin time and activated partial thromboplastin time of human blood

Different concentrations $(2.5,5$ and $10 \%)$ of crude extract produced dose-dependent and significant $(\mathrm{p}<0.001)$ increase in clotting time. Similarly, the addition of different concentrations $(2.5,5,10 \%)$ of crude extract into human blood $(n=5)$ caused significant $(\mathrm{p}<0.001)$ prolongation in prothrombin time of human blood sample as compared to control. The most profound increase in the prothrombin time was $80.6 \pm$ $3.2 \mathrm{sec}$ with $10 \%$ concentration of crude extract as compared to control i.e., $13.0 \pm 1.0 \mathrm{sec}$. Moreover, crude extract $(5$ and $10 \%)$ significantly $(\mathrm{p}<0.001)$ prolonged the activated partial thromboplastin time. Moreover, $10 \%$ concentration of crude extract produced pronounced effects of activated partial thromboplastin time (340 $\pm 30.2)$ as compared to the control $(23.0 \pm 1.0)$ (Table I).

Effect on clotting time, prothrombin time and activated partial thromboplastin time of rabbit blood

The crude extract significantly $(p<0.001)$ increase clotting time at of 5 and $10 \%$ concentrations with remarkable prolongation in clotting time of rabbit blood at $10 \%$ concentration $(53 \pm 2.6 \mathrm{~min})$ as compared to control (7.8 $\pm 1.02 \mathrm{~min})$. Similarly, aqueous methanol extract exhibited noteworthy $(\mathrm{p}<0.001)$ and dose-dependent $(2.5,5,10 \%)$ increase in prothrombin time. How- 
Table I

In vitro effects of aqueous methanolic extract of $B$. orthobotrys on different coagulation parameters

\begin{tabular}{|c|c|c|c|c|c|c|c|c|}
\hline \multirow[t]{3}{*}{ Parameters } & \multicolumn{8}{|c|}{ Aqueous methanolic extract (\%) } \\
\hline & \multicolumn{4}{|c|}{ Human } & \multicolumn{4}{|c|}{ Rabbit } \\
\hline & 0 & 2.5 & 5.0 & 10.0 & 0 & 2.5 & 5.0 & 10.0 \\
\hline $\begin{array}{l}\text { Clotting time } \\
\text { (min) }\end{array}$ & $5.0 \pm 0.5$ & $14.2 \pm 1.3^{\mathrm{b}}$ & $23.8 \pm 1.8^{\mathrm{a}}$ & $46.6 \pm 2.7 \mathrm{a}$ & $7.8 \pm 1.0$ & $14.4 \pm 1.3^{c}$ & $23.6 \pm 1.3^{a}$ & $53.0 \pm 2.6^{a}$ \\
\hline $\begin{array}{l}\text { Prothrombin time } \\
\text { (sec) }\end{array}$ & $13.0 \pm 0.9$ & $43.6 \pm 1.4^{\mathrm{a}}$ & $60.0 \pm 1.7 \mathrm{a}$ & $80.6 \pm 3.1^{a}$ & $12.6 \pm 0.7$ & $45.0 \pm 1.6^{\mathrm{a}}$ & $61.2 \pm 1.9 \mathrm{a}$ & $73.2 \pm 1.1^{\mathrm{a}}$ \\
\hline $\begin{array}{l}\text { Activated partial } \\
\text { thromboplastin } \\
\text { time (sec) }\end{array}$ & $23.0 \pm 0.9$ & $72.2 \pm 2.6^{\mathrm{ns}}$ & $143.4 \pm 10.1^{\mathrm{a}}$ & $340.0 \pm 30.2^{\mathrm{a}}$ & $21.8 \pm 1.2$ & $49.4 \pm 5.1^{\mathrm{ns}}$ & $109.6 \pm 5.4^{\mathrm{b}}$ & $406.0 \pm 30.1^{\mathrm{a}}$ \\
\hline
\end{tabular}

ever, increase in prothrombin time up to $(73.2 \pm 2.0 \mathrm{sec})$ was observed with $10 \%$ concentration as compared to control $(12.6 \pm 0.6 \mathrm{sec})$ (Table I). In the same manner, $2.5,5,10 \%$ of crude extract dose-dependently enhanced the activated partial thromboplastin time with most significant $(p<0.001)$ increase in the activated partial thromboplastin time at $10 \%$ solution (Table I).

\section{In vitro thrombolytic activity of $B$. orthobotrys on human and rabbit blood}

Aqueous methanolic extract of $B$. orthobotrys showed considerable $(p<0.001)$ and dose reliant increase in lysis of human blood clot at different concentrations of 2.5, 5 and $10 \%$. Moreover, at the highest concentration $(10 \%)$, extract showed more prominent lysis. Similarly, different concentrations $(2.5,5$ and $10 \%)$ of crude extract also displayed the noteworthy and dose-dependent effect on the thrombolysis of rabbit blood (Figure 1).

Effect of B. orthobotrys on in vivo bleeding time and clotting time after single dose administration

Treatment with crude extract produced significant $(p<0.001)$ increase in bleeding time at 25, 50 and 100 $\mathrm{mg} / \mathrm{kg}$ doses after 30, 60 and $90 \mathrm{~min}$ of administration. (Table II). However, most prominent effects were produced at $100 \mathrm{mg} / \mathrm{kg}$ after $90 \mathrm{~min}$ of dose administration. Similarly, methanolic extract dose-dependently produced prolongation of clotting time with most pronounced effects at a dose of $100 \mathrm{mg} / \mathrm{kg}$ after $90 \mathrm{~min}$ of administration (Table II). The dose of 25 and $50 \mathrm{mg} /$ $\mathrm{kg}$ produced prolongation of clotting time but the most pronounced effects were produced at the concentration of $100 \mathrm{mg} / \mathrm{kg}$ after $90 \mathrm{~min}$ of administration.

\section{Effect of B. orthobotrys on different coagulation parameters after 7 days of treatment}

There was significant $(p<0.01-0.001)$ increase in bleeding time, clotting time, prothrombin time and activated partial thromboplastin time in animals treated with extract at doses of 25,50 and $100 \mathrm{mg} / \mathrm{kg}$, orally for seven days when compared to the control at day 7 of the study. On day 7 , significant $(p<0.05-0.001)$ rise in

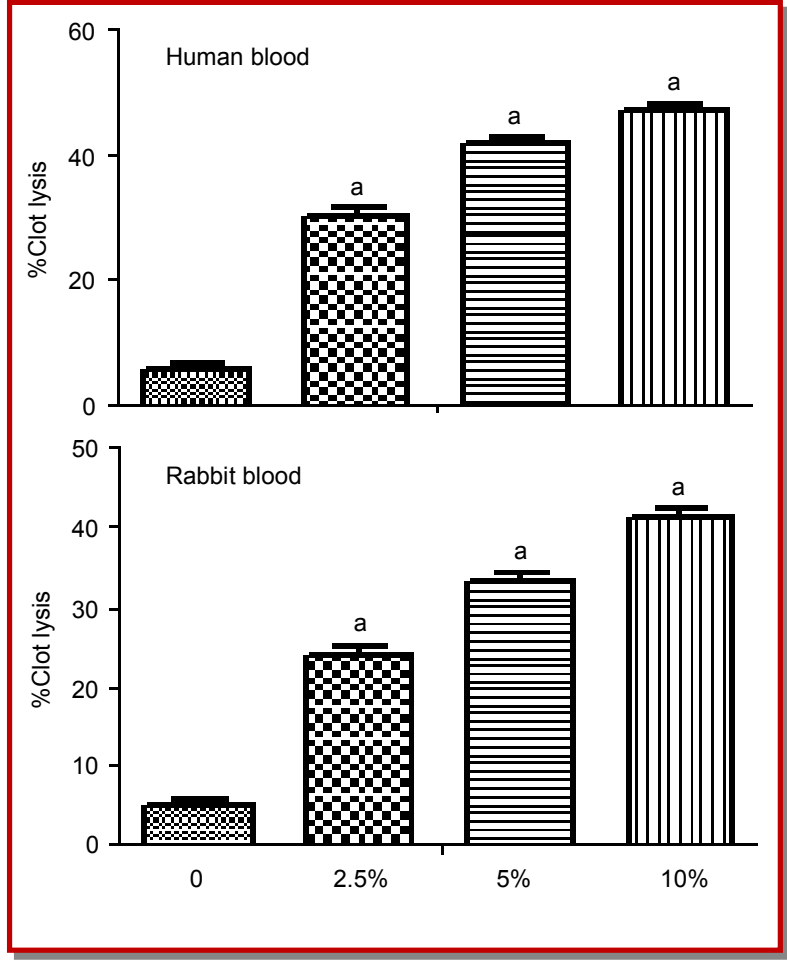

Figure 1: Effect of aqueous methanolic extract of Berberis orthobotrys on human (upper) or rabbit (lower) blood clot lysis done by One-way ANOVA where a $p<0.001$

bleeding time, clotting time, prothrombin time and activated partial thromboplastin time was observed at 50 and $100 \mathrm{mg} / \mathrm{kg}$ doses, but the dose of $25 \mathrm{mg} / \mathrm{kg}$ only prolong the clotting time and APTT significantly $(p<0.001)$ when compared to control as depicted in (Table III).

\section{Phytoconstituents in the aqueous methanolic extract of B. orthobotrys through HPLC}

The HPLC analysis of $B$. orthobotrys crude extract revealed the presence of quercetin, gallic acid, pcoumaric acid, vanillic acid and 4-hydroxy-3-methoxy benzoic acid as illustrated in (Table IV). 
Table II

Effects of B. orthobotrys extract on in vivo bleeding and cloting times in rabbit

\begin{tabular}{|crrrrrr|}
\hline \multirow{2}{*}{$\begin{array}{c}\text { Time } \\
(\mathrm{min})\end{array}$} & \multicolumn{3}{c}{ Bleeding time $(\mathrm{sec})$} & \multicolumn{3}{c|}{ Clotting time (sec) } \\
\cline { 2 - 7 } & $2.5 \%$ & $5 \%$ & $10 \%$ & $2.5 \%$ & $5 \%$ & $10 \%$ \\
\hline 0 & $32.6 \pm 2.7$ & $32.6 \pm 2.7$ & $32.6 \pm 2.7$ & $242.0 \pm 25.8^{\mathrm{a}}$ & $237.0 \pm 23.8^{\mathrm{a}}$ & $260.0 \pm 21.7^{\mathrm{a}}$ \\
30 & $41.0 \pm 1.7^{\mathrm{a}}$ & $44.8 \pm 2.9^{\mathrm{a}}$ & $53.8 \pm 2.5^{\mathrm{a}}$ & $323.0 \pm 9.3^{\mathrm{a}}$ & $341.2 \pm 3.5^{\mathrm{a}}$ & $359.8 \pm 3.5^{\mathrm{a}}$ \\
60 & $54.0 \pm 1.5^{\mathrm{a}}$ & $60.4 \pm 2.9^{\mathrm{a}}$ & $69.6 \pm 1.9^{\mathrm{a}}$ & $348.8 \pm 2.3^{\mathrm{a}}$ & $352.8 \pm 7.1^{\mathrm{a}}$ & $378.0 \pm 2.2^{\mathrm{a}}$ \\
90 & $63.2 \pm 1.1^{\mathrm{a}}$ & $67.2 \pm 1.5^{\mathrm{a}}$ & $78.6 \pm 1.1^{\mathrm{a}}$ & $362.0 \pm 2.2^{\mathrm{a}}$ & $370.0 \pm 1.7^{\mathrm{a}}$ & $411.4 \pm 11.2^{\mathrm{a}}$ \\
\multicolumn{2}{l}{ Results are expressed as means \pm SEM. Two-way ANOVA was applied to analyze the data. Where, ap<0.001 vs control (0 min) }
\end{tabular}

\section{Table III}

Effects of B. orthobotrys extract on different coagulation parameters after 7 days in vivo administration

\begin{tabular}{|c|c|c|c|c|}
\hline \multirow[t]{2}{*}{ Parameters } & \multicolumn{4}{|c|}{ Treatment groups (aqueous methanolic extract) } \\
\hline & Control & $2.5 \%$ & $5 \%$ & $10 \%$ \\
\hline Bleeding time (sec) & $40.3 \pm 2.9$ & $52.0 \pm 1.7 \mathrm{c}$ & $68.6 \pm 3.8^{a}$ & $77.0 \pm 2.0^{\mathrm{a}}$ \\
\hline Clotting time (sec) & $240.0 \pm 34.6$ & $358.0 \pm 4.4^{\mathrm{b}}$ & $375.0 \pm 2.5^{b}$ & $392.3 \pm 1.8^{\mathrm{a}}$ \\
\hline Prothrombin time $(\mathrm{sec})$ & $16.0 \pm 1.7$ & $27.3 \pm 1.2^{b}$ & $38.0 \pm 1.7 \mathrm{a}$ & $52.7 \pm 1.4^{\mathrm{a}}$ \\
\hline Activated partial thromboplastin time (sec) & $32.0 \pm 1.7$ & $56.0 \pm 4.4^{\mathrm{b}}$ & $82.3 \pm 1.8^{a}$ & $108.3 \pm 6.1^{\mathrm{a}}$ \\
\hline
\end{tabular}

\section{Table IV}

Phytoconstituents identified in crude extract of Berberis orthobotrys using HPLC

\begin{tabular}{|ccccl|}
\hline $\begin{array}{c}\text { Peak } \\
\text { No. }\end{array}$ & $\begin{array}{c}\text { RT } \\
(\mathrm{min})\end{array}$ & $\begin{array}{c}\text { Area } \\
\text { count }\end{array}$ & $\begin{array}{c}\text { Amount } \\
(\mathrm{ppm})\end{array}$ & Compounds \\
\hline 4 & 2.9 & 28.6 & 1.5 & Quercitin \\
7 & 4.9 & 319.9 & 1.1 & Gallic acid \\
12 & 13.2 & 71.9 & 4.4 & Vanillic acid \\
13 & 14.1 & 237.0 & 3.1 & p-coumaric acid \\
14 & 17.7 & 246.0 & 26.0 & $\begin{array}{l}\text { 4-hydroxy-3- } \\
\text { methoxy benzoic } \\
\text { acid }\end{array}$ \\
\hline
\end{tabular}

\section{Discussion}

In the current study, results of in vitro and in vivo studies illustrated that crude extract of $B$. orthobotrys produced a significant increase in prothrombin time as compared to control. Prolonged prothrombin time indicates blockade of the tissue factor pathway, which relies on the presence of factor VII, which in turn depends upon activation by vitamin $\mathrm{K}$ and formerly it has been reported that the warfarin and other vitamin $\mathrm{K}$ antagonists lead to prolonged prothrombin time. The anticoagulant effect may be endorsed to coumaric acid that has been noted in HPLC screening of crude extract of $B$. orthobotrys and antecedently coumarin has been reported to inhibit vitamin $\mathrm{K}$-dependent clotting factors activation such as clotting factors II, VII, IX and X (Rang et al., 2007). Moreover, some berberis species namely $B$. aristata and B. lyceum (Sabir et al., 2014) have been reported to possess anti-coagulant activity due to the presence of coumarins.

Activated partial thromboplastin time assay is used to assess intrinsic clotting index and coagulation factors such as VIII, IX, XI, XII (Azevedo et al., 2007). Administration of $B$. orthobotrys aqueous methanolic extract revealed a highly significant increase in activated partial thromboplastin time in human and rabbit's serum in both in vitro and in vivo assays. As intrinsic clotting activity is measured by activated partial thromboplastin time test and usually increased values of activated partial thromboplastin time represents a deficiency in factors VII, IX, XII, XIII and von Willebrand's factor (Laffan and Bradshaw, 1995) it could be proposed that $B$. orthobotrys has inhibitory effects on these factors.

Thrombosis results when activated platelets from platelet to platelet bonds and also bind to leukocytes and form a complex process of plaque formation and growth. By pharmacological means, thrombolysis is the breakdown of blood clots. For this reason, it is collectively referred to as 'clot bursting'. Fibrinogen and fibrin contained in a clot is lysed by plasmin which is a fibrinolytic agent (Das et al., 2013). Thus in the present study, in vitro thrombolytic activity showed that $B$. orthobotrys aqueous methanolic extract possesses notable ability to break down blood clot thus strengthening 
its anticoagulant potential.

Polyphenolic compounds are a large group of organic secondary plant metabolites which have been divided into several classes including hydroxy benzoic acid, hydroxy cinnamic acid, coumarins, xanthones, stilbenes, anthraquinones, lignans and flavonoids (Manach et al., 2004). Formerly, the polysaccharide phenolic protein complex has been found to exhibit both anticoagulant and procoagulant effects on blood coagulation system (Pawlaczyk et al., 2011). Also, Pawlaczyk et al. (2011) proved phenolic polysaccharide isolated from Erigeron canadensis as a potentially useful anticoagulant and antiplatelet agents. HPLC screening of $B$. orthobotrys revealed the presence of quericitin, gallic acid, 4hydroxy-3-methoxy benzoic acid and p-coumaric acid.

Coumarin is derived from a variety of plants used as an anticoagulant. In the blood coagulation cascade, coumarin works by inhibiting the calcium activity. Previously, it has been reported that coumarins have antithrombotic and thrombolytic activity, therefore antithrombotic activity of test plant extract might be due to its phenolic coumarins and marked increase of prothrombin time and activated partial thromboplastin time is apparently caused by the interference of procoagulant action of calcium by phenolic compounds found in crude extract of B. orthobotrys. Previously, it has also been reported that flavonoids have thrombolytic activity (Adiba et al., 2013) and quercetin, a flavonoid that is also a strong free radical terminator and can aid to reduce atherosclerosis that leads to heart attack and stroke (Koffuor and Amoateng, 2011). Thus, the anticoagulant activities exhibited by B. orthobotrys may be due to the presence of these constituents thus supporting its traditional use in cardiac patients.

\section{Conclusion}

The aqueous methanolic extract of $B$. orthobotrys shows antithrombotic potential.

\section{Ethical Issue}

All experimental procedures were approved by the Institutional Animal Ethical Committee, College of Pharmacy, and University of Sargodha and were performed according to the standard procedures of National Research Council (NRC, 1996).

\section{Conflict of Interest}

The authors have no conflicts of interest.

\section{Acknowledgement}

All authors are grateful to the University of Sargodha for providing some financial support for this study.

\section{References}

Adiba M, Jahan N, Hussain IMT. Evaluation of antithrombotic activity of Duqu (Peucedanum Grande Cb Clarke) in animal model. WJPPS. 2013; 2: 3915-28.

Alamgeer, Akhtar MS, Jabeen Q, Akram M, Mushtaq MN, Salma U. Antihypertensive activity of aqueous-methanol extract of Berberis Orthobotrys Bien Ex Aitch in rats. Trop J Pharm Res. 2013; 12: 393-99.

Alamgeer, Ain Q, Hasan U, Asif H. Antithrombotic activity of Mentha longifolia in animal model. Bangladesh J Pharmacol. 2018; 13: 67-73.

Alamgeer, Asif H, Rasool S. Antithrombotic potential of Berberis calliobotrys extract. Bangladesh J Pharmacol. 2016; 11: 776-83.

Anderson FA, Spencer FA. Risk factors for venous thromboembolism. Circulation 2003; 107(Suppl): 1-9.

Azevedo APS, Farias JC, Costaetal GC. Anti-thrombotic effect of chronic oral treatment with Orbignya phalerata Mart. J Ethnopharmacol. 2007; 111: 155-59.

Bhattarai NK. Traditional phytotherapy among the Sherpas of Helambu, central Nepal. J Ethnopharmacol.1989; 27: 45-54.

Das A, Dewan SMR, Ali R, Debnath PD, Billah M. Investigation of in-vitro thrombolytic potential of ethanolic extract of Momordica charantia fruits: An anti-diabetic medicinal plant. Der Pharmacia Sinica. 2013; 4: 104-08.

Dickneite G, Seiffe D, Diehl KH, Rogers M, Czech J. Pharmacological characterization on a new 4-amidinophenyl-alanine thrombin-inhibitor (CRC220). Thromb Res. 1995; 77: 357-68.

Elg M, Carlson S, Gustafsson D. Effects of agents used to treat bleeding disorders on bleeding time prolonged by a very high dose of direct thrombin inhibitor in anesthetized rats and rabbits. Thromb Res. 2001; 101: 159-70.

Gou YL, Ho AL, Rowlands DK, Chung YW, Chan HC. Effects of Bak Foong pill on blood coagulation and platelet aggregation. Biol Pharm Bull. 2003; 26: 241-46.

Jagtap A, Sancheti JS, Phadke AS. Antiplatelet and antithrombotic activity of ethanolic extract of Emblica ribes. Int J Res Phytochem Pharmacol. 2012; 2: 150-56.

Jain S, Dangi CBS, Kaur M, Singh H , Peter J, Kosta S. Plant as anticogulant/antithrombotic agent. World J Pharm Res. 2014; 3: 4573-83.

Khan SW, Khatoon, S. Ethnobotanical studies on useful trees and shrubs of Haramosh and Bugrote valleys in Gilgit Northern areas of Pakistan. Pakistan J Bot. 2007; 39: 699-710.

Khanna S, Gupta SR, Grover JK. Effect of long-term feeding of tulsi on reproductive performance of adult albino rats. Ind J Exp Biol. 1986; 24: 302-04.

Klafke JZ, Arnoldi da Silva M, Fortes Rossato M, Trevisan G, Walker B, Isabel C, Martins Leal CA, Olschowsky Borges D, Chitolina Schetinger MR, Noal Moresco R, Medeiros Frescura Duarte MM. Antiplatelet, antithrombotic, and fibrinolytic activities of Campomanesia xanthocarpa. Evid 
Based Complement Altern Med. 2012; 2012.

Koffuor GA, Amoateng P. Anti-oxidant and anticoagulant properties of Phyllanthus fraternus GL Webster (Family: Euphorbiaceae). J Pharmacol Toxicol. 2011; 6: 624-36.

Laffan MA, Bradshaw AE. Investigation of haemostasis. In: Practical haematology. Dacie JV, Lewis SM (eds.). 8th ed. Edinburgh, Churchill Livingstone, 1995, pp 297-315.

Mahmood A, Mahmood A, Shaheen H, Qureshi RA, Sangi Y, Gillani SA. Ethnomedicinal survey of plants from district Bhimber Azad Jammu and Kashmir, Pakistan. J Med Plant Res. 2011; 5: 2348-60.

Manach C, Scalbert A, Morand C, Rémésy C, Jimenez L. Polyphenols: Food sources and bioavailability. Am J Clin Nutr. 2004; 79: 727-47.

Pawlaczyk I, Czerchawski L, Kuliczkowski W, Karolko B, Pilecki W, Witkiewicz W, Gancarz R. Anticoagulant and anti -platelet activity of polyphenolic-polysaccharide preparation isolated from the medicinal plant Erigeron canadensis L. Thromb Res. 2011; 127: 328-40.

Prasad S, Kashyap RS, Deopujari JY, Purohit HJ, Taori GM, Daginawala HF. Development of an in vitro model to study clot lysis activity of thrombolytic drugs. Thromb J. 2006; 4: 14 .

Rang HP, Dale MM, Ritter JM, Flower RJ. Haemostasis and thrombosis. In: Rang and Dale's Pharmacology. 6th ed. Churchill Livingstone (Elsevier), 2007, pp 332-45.

Sabir I, Khavandi K, Brownrigg J, Camm AJ. Oral anticoagulants for Asian patients with atrial fibrillation. Nat Rev Cardiol. 2014; 11: 290-303.

Tokusoglu O, Unal MK, Yildirum Z. HPLC-UV and GC-MS characterization of the flavonol aglycons quercetin, kaempferol and myrecetin in tomato and tomato pastes and other tomato-based products. Acta Chromatogr. 2003; 13: 196-207. 